\title{
SATURAÇÃO POR BASES E HÍBRIDOS DE MILHO SOB SISTEMA PLANTIO DIRETO'
}

\author{
Renato de Mello Prado* \\ ${ }^{2}$ Pós-Graduando do Depto. de Solos e Adubos - FCAV/UNESP, Via de acesso Prof. Paulo Donato Castellane, s/n - \\ CEP: 14870-000 - Jaboticabal, SP. \\ *Autor correspondente <rmprado@fcav.unesp.br>
}

\begin{abstract}
RESUMO: O conhecimento dos híbridos adaptados a cada condição de reação do solo em sistema plantio direto é de significativa importância técnica. Para avaliar o comportamento de híbridos de milho sob sistema plantio direto, quanto a alguns componentes de rendimento, submetidos a níveis de saturação por bases, foram conduzidos dois experimentos no V\% 45 e V\% 65 em área com 4 anos em sistema plantio direto, na região dos cerrados, em Uberaba, MG. Os experimentos foram desenvolvidos no delineamento em blocos ao acaso, com quatro repetições. Os sete tratamentos foram constituídos pelos seguintes híbridos de milho: Z 8474, BR 3123, AG 122, C 333, D 657, Exceller e P 3071. Na média dos híbridos de milho estudados a saturação por bases de $65 \%$ foi a que mais contribuiu para os incrementos nos componentes do rendimento e nos rendimentos de grãos. Os híbridos apresentaram comportamento diferenciado no rendimento de grãos, destacando-se na saturação por bases $65 \%$, os híbridos P 3071 e o Z 8474 e no nível $45 \%$ destacou-se o híbrido C 333. A utilização de híbridos específicos para cada nível de saturação por bases mostrou-se uma importante ferramenta para a maximização do rendimento da cultura do milho em sistema plantio direto no cerrado.
\end{abstract}

Palavras-chave: Zea mays, adaptação, acidez do solo, componentes do rendimento, rendimentos de grãos

\section{BASE SATURATION AND CORN HYBRIDS UNDER NO-TILLAGE SYSTEM}

\begin{abstract}
The knowledge of the hybrids of suitable maize to each condicion of the ground in under notillage is of significant importance technique. To evaluate the response of corn hybrids to base saturation levels (V\%), two experiments were performed with V\% equal to 45 and 65, in cerrado areas of Uberaba, MG, Brazil, four years under no-tillage. A completely randomized block design was used, with four replications. Seven corn hybrids represent the treatments: Z 8474, BR3123, AG 122, C 333, D 657, Exceller and P 3071. The results showed that the base saturation of $65 \%$ contributed more for the increments in yield components and for the grain yield than the $45 \%$ base saturation level. The hybrids presented different yield responses, the highest beeing for the $65 \%$ base saturation treatment: P 3071 and Z 8474 and 2); for the $45 \%$ base saturation treatment: $\mathrm{C} 333$. Choosing the right hybrids for each base saturation level is an important criterium to maximize corn yields under no-tillage in the cerrado region of Brazil.

Key words: Zea mays, adaptation, acid soil, yield components, grain yields
\end{abstract}

\section{INTRODUÇÃO}

Atualmente a agricultura vem passando por transformações tecnológicas significativas em função da necessidade de conciliar o manejo conservacionista do solo com a busca constante da redução dos custos de produção. Dessa forma, o sistema plantio direto intensificou-se no Brasil, particularmente na região dos cerrados. Dos dez milhões de hectares atualmente ocupados por culturas anuais nos cerrados, aproximadamente dois milhões estão sob plantio direto, dados significativos para um período de apenas 16 anos (Resck, 1998).

Com a adoção da prática do plantio direto no cerrado, tem se verificado um número elevado de áreas agrícolas, cujos solos apresentam saturação por bases (V\%) na faixa de $45 \%$, ou até menos, mas, muitas vezes, com produções elevadas. Tem-se considerado que a complexação do alumínio pelos compostos orgânicos oriundos da decomposição dos resíduos vegetais acumulados na superfície do solo é que provoca esse comportamento favorável das culturas em solos mais ácidos (Hue et al., 1986; Santos, 1999).

Por outro lado, a saturação por bases em valores mais elevados, nos solos com sistema plantio direto implantados a menos de cinco anos, pode trazer benefícios ao sistema, principalmente porque os complexos orgânicos não atingiram níveis quantitativos e qualitativos suficientes devido ao acúmulo lento do carbono orgânico total nos solos da região dos cerrados.

Resultados de pesquisa apontam para uma resposta diferencial de certos híbridos de milho à calagem, principalmente no sistema plantio direto no Sul do Brasil (Sá, 1993), enquanto que na região dos

${ }^{1}$ Trabalho apresentado no $6^{\circ}$ Encontro Nacional de Plantio Direto na Palha, Brasília, 1998. 
cerrados poucos trabalhos têm sido realizados visando esclarecer os efeitos entre os híbridos de milho submetida a níveis de saturação por bases especialmente em sistema plantio direto. Raij et al. (1998) relataram a mesma resposta positiva de híbridos de milho à calagem independentemente se tolerante (BR 201, IAC 7974, C 525) ou sensível (AG 401, IAC 8214; DINA 170) à acidez do solo em experimento conduzido no sistema convencional de preparo do solo.

Portanto o conhecimento dos híbridos adaptados a cada condição de solo é de significativa importância técnica que se reflete na econômica, tendo em vista os incrementos na produtividade da cultura sem aumento desnecessário de custo no sistema de produção.

O presente trabalho teve como objetivo avaliar a resposta de híbridos de milho, cultivados no sistema plantio direto na região dos cerrados, em solo submetido a dois níveis de saturação por bases (45\% e $65 \%$ ), em relação a alguns componentes de rendimento.

\section{MATERIAL E MÉTODOS}

O experimento foi realizado em duas áreas na Agropecuária Nossa Senhora Aparecida, em Uberaba, MG, no ano agrícola 1997/98. O solo ocorrente nas áreas dos dois experimentos é um Latossolo Vermelho distrófico típico, textura muito argiloso. As análises químicas e físicas são apresentadas na TABELA 1.

$O$ delineamento experimental utilizado nos dois experimentos com parâmetros de acidez diferentes, no caso, a saturação por bases iguais a $45 \%$ e $65 \%$, foi o de blocos ao acaso com 4 repetições e com sete tratamentos constituídos por híbridos de milho amplamente cultivados na região dos cerrados: Z 8474, BR 3123, AG 122, C 333, D 657, Exceller e P 3071.

Nos dois experimentos o manejo foi o mesmo, sendo que a semeadura (25/10/97) foi mecanizada, com densidade final de 55000 plantas ha ${ }^{-1}$, utilizando como cobertura morta o milheto cultivado no inverno. A adubação de base foi de $400 \mathrm{~kg} \mathrm{ha}^{-1}$ da fórmula 04$30-16+0,5 \% \mathrm{Zn}+0,3 \% \mathrm{Mn}$ e em cobertura aplicou-se 100 $\mathrm{kg} \mathrm{ha}^{-1}$ de $\mathrm{N}$ na época da quinta folha exposta. As parcelas foram constituídas por 8 linhas espaçadas de $0,80 \mathrm{~m}$ com $20 \mathrm{~m}$ de comprimento, sendo consideradas as 6 linhas centrais como área útil, para cada experimento. Os dois experimentos foram instalados em áreas próximas, cultivadas em dois níveis de saturação, cuja escolha visou local com sistema plantio direto na fase inicial (quarto ano agrícola), sendo que nos três primeiros anos foram cultivados, nas duas áreas, soja tardia no verão e no quarto ano o milho, sempre com aveia preta no inverno.

Avaliou-se o número de dias para o florescimento e, na colheita (28/03/98) obteve-se 0 rendimento de grãos, peso médio das espigas, número de grãos por espiga, peso de 1000 grãos, peso de grãos por espiga e a prolificidade.

Para a análise estatística foram realizadas as análises de variância conjunta e individual. Inicialmente procedeu-se a análise conjunta; para isto foram selecionadas apenas as características cujos quadrados médios residuais não diferiram em mais de sete vezes de um experimento para o outro (Gomes, 1985). E para comparação das médias dos tratamentos (híbridos de milho) dentro de cada experimento (nível de saturação por bases) utilizou-se o teste de Tukey $(P<0,05)$.

\section{RESULTADOS E DISCUSSÃO}

$\mathrm{Na}$ análise conjunta, através do teste $\mathrm{F}$, envolvendo os dois experimentos, observou-se efeito significativo para os tratamentos (híbridos), para o $\mathrm{V} \%$ e a sua interação para todas as variáveis estudadas, tais como: rendimento $(P<0,01)$; peso médio de espiga $(P<0,05)$, número de grãos por espiga $(P<0,01)$ e peso de 1000 grãos $(P<0,01)$. A exceção ocorreu para número de dias para florescimento e a prolificidade $(P>0,05)$, independentes, portanto, do nível de saturação por bases, indicando que tais variáveis são próprias dos híbridos testados.

A presença da interação significativa, pela análise conjunta, entre os híbridos de milho (planta) e dos níveis de saturação por bases (solo) está de acordo com Eberhar \& Russel (1966) que observaram que as mesmas variedades submetidas a ambientes distintos, como diferentes níveis de fertilidade do solo, não apresentam as mesmas respostas. Sá (1993) obteve resultados semelhantes em sistema plantio direto no Sul

TABELA 1 - Resultados das análises química e física do solo da área experimental sob dois níveis de saturação por bases, na camada superficial $(0-20 \mathrm{~cm}$ de profundidade) em sistema plantio direto.

\begin{tabular}{|c|c|c|c|c|c|c|c|c|c|c|c|}
\hline $\mathrm{pH}$ & $\mathrm{MO}$ & $\mathrm{P}$ & K & $A l^{+3}$ & $\mathrm{Ca}^{+2}$ & $\mathrm{Mg}^{+2}$ & $\mathrm{H}+\mathrm{Al}$ & SB & $\mathrm{T}$ & V & $\mathrm{m}$ \\
\hline \multicolumn{12}{|c|}{$\mathrm{H}_{2} \mathrm{O}$} \\
\hline & $\mathrm{g} \mathrm{dm}^{-3}$ & ---- & $m^{-3}---$ & -- & ------ & ---- r r n n & $\mathrm{dm}^{-3}$ & --... & ---- & ---- & $6-----$ \\
\hline \multicolumn{12}{|c|}{ Área com V\% 65} \\
\hline 5,4 & 21 & 6 & 60,0 & 2,0 & 28,5 & 7,5 & 22,5 & 37,5 & 59,0 & 63,6 & 5,1 \\
\hline \multicolumn{12}{|c|}{ Área com V\% 45} \\
\hline 4,9 & 24 & 5 & 53,0 & 8,0 & 18,5 & 7,1 & 36,0 & 27,0 & 61,3 & 44,1 & 22,9 \\
\hline
\end{tabular}

Obs.: P e K extraído pelo Mehlich-1 1N (Defelipo \& Ribeiro, 1981); Ca, Mg e Al extraído com KCl 1N (Defelipo \& Ribeiro, 1981); H+Al extraído com acetato de cálcio 1N, pH 7,0 (Raij \& Quaggio, 1983); matéria orgânica (MO) determinado pelo método Walkley \& Black (Defelipo \& Ribeiro, 1981). 
do Brasil, concluindo que o uso de híbridos de milho adaptados a cada situação específica de nível de saturação por bases mostrou ser uma excelente ferramenta na busca por produtividade com boa relação custo/benefício. Portanto, existe uma relação importante entre o híbrido específico e a saturação por bases de solo.

Verifica-se pela TABELA 2 que de forma geral, o rendimento de grãos dos híbridos no V\% 65 $\left(6248 \mathrm{~kg} \mathrm{ha}^{-1}\right)$ foi maior do que no V\% $45\left(4675 \mathrm{~kg} \mathrm{ha}^{-1}\right)$, possivelmente devido às condições favoráveis do solo e às exigências distintas entre os híbridos testados; portanto, esses resultados discordam de Miyazawa et al.(1996); Pöttker \& Ben (1998) e Caires et al.(1999) que relatam baixa resposta do milho à calagem em sistema plantio direto.

As diferenças entre estes resultados podem ser devidas aos híbridos, que não são os mesmos, sendo que Pöttker \& Ben (1998) e Caires et al. (1999) estudaram os híbridos de milho AG 9012 e C 901, respectivamente, e também pelo tempo de sistema plantio direto, sendo que no presente trabalho o mesmo estava no $4^{\circ}$ ano, enquanto que nos trabalhos citados o sistema está consolidado, chegando até 15 anos, implicando que nessa fase o

TABELA 2 - Valores médios do rendimento de grãos, peso de espiga e do número de grãos por espiga sob níveis de saturação por bases em sistema plantio direto.

\begin{tabular}{lccc}
\hline \multicolumn{4}{c}{ Área com V\% 65 } \\
\hline Tratamentos & $\begin{array}{c}\text { Rendimento } \\
\text { de grãos }\end{array}$ & $\begin{array}{c}\text { Peso de } \\
\text { espiga }\end{array}$ & $\begin{array}{c}\text { Número de } \\
\text { grãos por } \\
\text { espiga }\end{array}$ \\
\hline P 3071 & $\mathrm{kg} \mathrm{ha}^{-1}$ & $\mathrm{~g}$ \\
Z 8474 & $7.974 \mathrm{a}^{1}$ & $168 \mathrm{a}$ & $436 \mathrm{a}$ \\
Exceller & $7.285 \mathrm{ab}$ & $133 \mathrm{ab}$ & $440 \mathrm{a}$ \\
BR 3123 & $6.495 \mathrm{bc}$ & $132 \mathrm{~b}$ & $378 \mathrm{~b}$ \\
C 333 & $5.810 \mathrm{c}$ & $123 \mathrm{~b}$ & $325 \mathrm{bc}$ \\
AG 122 & $5.471 \mathrm{c}$ & $119 \mathrm{~b}$ & $325 \mathrm{bc}$ \\
\hline DINA 652 & $5.356 \mathrm{c}$ & $116 \mathrm{~b}$ & $300 \mathrm{c}$ \\
\hline Média Ge ral & 6.248 & $114 \mathrm{~b}$ & $298 \mathrm{c}$ \\
CV (\%) & 8,7 & 129 \\
\hline & Área com V\% 45 & 358 \\
\hline C 333 & $5521 \mathrm{a}$ & $121 \mathrm{a}$ & $331 \mathrm{a}$ \\
\hline BR 3123 & $5315 \mathrm{ab}$ & $116 \mathrm{a}$ & $312 \mathrm{ab}$ \\
AG 122 & $5005 \mathrm{abc}$ & $108 \mathrm{a}$ & $310 \mathrm{ab}$ \\
Z 8474 & $4391 \mathrm{abc}$ & $115 \mathrm{a}$ & $265 \mathrm{~b}$ \\
P 3071 & $4215 \mathrm{bc}$ & $115 \mathrm{a}$ & $295 \mathrm{ab}$ \\
\hline DINA 657 & $4173 \mathrm{bc}$ & $114 \mathrm{a}$ & $341 \mathrm{a}$ \\
Exceller & $4136 \mathrm{c}$ & $115 \mathrm{a}$ & $300 \mathrm{ab}$ \\
\hline Média Geral & 4675 & 115 & 308 \\
CV (\%) & 12,1 & 11,9 & 5,6 \\
\hline
\end{tabular}

${ }^{1}$ Média seguidas pela mesma letra não diferem significativamente pelo teste de Tukey $(\mathrm{P}<0,05)$ e a umidade dos grãos corrigida a $0,13 \mathrm{~kg} \mathrm{~kg}^{-1}$.

*; ** Resultado significativo $(\mathrm{P}<0,05)$ e $(\mathrm{P}<0,01)$ respectivamente. sistema está praticamente estável e os benefícios dos compostos orgânicos hidrossolúveis citados por Santos (1999) na amenização da acidez do solo e consequentemente na absorção de nutrientes pela planta, encontram-se ativos em qualidade e quantidade.

Pela análise individual dos experimentos, especificamente, no V\% 65 o rendimento de grãos do híbrido P 3071 (7974 kg ha-1) diferiu significativamente dos demais com exceção do Z 8474 (7285 kg ha-1), sendo que esses dois híbridos foram em média $25 \%$ superiores aos demais. No V\% 45 o cultivar C 333 foi superior aos demais, porém não diferiu significativamente de BR 3123, AG 122 e Z 8474, sendo tais híbridos, em média, $18 \%$ superiores aos demais híbridos avaliados (TABELA 2). Portanto, para o sistema plantio direto no cerrado, principalmente aqueles na fase inicial compreendendo os primeiros 4 anos, a saturação por bases mostrou-se importante na produção da cultura do milho. Neste sentido, esses resultados mostram que parâmetros de solo ligados com as propriedades químicas, especialmente a saturação por bases são de extrema importância no sistema plantio direto e devem ser monitorado constantemente, o que concorda com Peche Filho (1999) que coloca o V\% como critério para avaliar a qualidade do sistema plantio direto. Caires et al (2000), estudando os efeitos da calagem no sistema plantio direto em Latossolo Vermelho-Escuro no sul do Brasil, em um sistema de rotação de culturas (soja, milho, trigo e triticale), concluíram que o método de elevação do V\% para 65 em amostras de solo coletadas na profundidade de 0-20 cm, apresenta estimativa adequada para a recomendação de calcário.

Todos os componentes do rendimento analisados, como peso de espiga, número de grãos por espiga (TABELA 2), peso de 1000 grãos e peso de grãos por espiga (TABELA 3) foram superiores no $\mathrm{V} \% 65$ do que em relação ao V\% 45. Este resultado explica a superioridade do V\% 65 em termos de rendimento de grãos (TABELA 2).

Observa-se ainda que, de uma forma geral, dentro de cada nível de saturação por bases, os híbridos de milho com maior rendimento de grãos (TABELA 2) também apresentaram as melhores posições dentre os componentes do rendimento analisados (TABELAS 2 e 3).

Para a característica prolificidade, os híbridos de milho apresentaram valores superiores no V\% $65(0,99)$ comparado a $\mathrm{V} \% 45 \quad(0,94)$, porém sem diferença significativa. No V\% 65 o híbrido BR $3123(1,02)$ foi mais prolífico, porém não diferiu dos demais (TABELA 3). Para ○ V\% 45 não houve diferença significativa entre os tratamentos, entretanto o C 333 apresentou tendência de ser mais prolífico $(0,99)$. Como houve diferenças entre os híbridos no rendimento de grãos, esperava-se o mesmo para prolificidade, o que não ocorreu, indicando que a prolificidade não foi importante para o rendimento do milho, contrariando Magalhães \& Silva (1987), que afirmaram que os incrementos da prolificidade acarretariam em aumento na produção do milho. 
TABELA 3 - Valores médios do peso de 1000 grãos, peso de grãos por espiga, prolificidade e número de dias para florescimento sob níveis de saturação por bases, em sistema plantio direto.

\begin{tabular}{|c|c|c|c|c|}
\hline \multicolumn{5}{|c|}{ Área com V\% 65} \\
\hline Tratamento & $\begin{array}{c}\text { Peso } \\
\text { de } 1000 \\
\text { grãos }\end{array}$ & $\begin{array}{l}\text { Peso de } \\
\text { grãos por } \\
\text { espiga }\end{array}$ & Prolificidade & $\begin{array}{c}\text { Dias para } \\
\text { florescimento }\end{array}$ \\
\hline \multicolumn{5}{|c|}{$\underline{g}$} \\
\hline P 3071 & $266 \mathrm{a}$ & $152 \mathrm{a}$ & $1,00 a b$ & $61 \mathrm{bc}$ \\
\hline Z 8474 & $219 b$ & $135 a b$ & $0,99 a b$ & $61 \mathrm{bc}$ \\
\hline Exceller & $232 a b$ & $118 \mathrm{abc}$ & $0,95 \mathrm{~b}$ & $58 \mathrm{c}$ \\
\hline BR 3123 & $240 \mathrm{ab}$ & 92 bc & $1,02 \mathrm{a}$ & $68 \mathrm{a}$ \\
\hline C 333 & $226 b$ & $92 \mathrm{c}$ & $0,99 a b$ & $64 a b$ \\
\hline AG 122 & $240 \mathrm{ab}$ & $92 \mathrm{c}$ & $0,99 a b$ & $64 a b$ \\
\hline DINA 657 & $237 \mathrm{ab}$ & $91 \mathrm{c}$ & $1,00 a b$ & $63 \mathrm{abc}$ \\
\hline $\begin{array}{l}\text { Média } \\
\text { Geral }\end{array}$ & 237 & 112 & 0,99 & 63 \\
\hline CV (\%) & 6,9 & 15,0 & 2,9 & 4,1 \\
\hline \multicolumn{5}{|c|}{ Área com V\% 45} \\
\hline C 333 & 237 a & 97 a & 0,99 a & $64 \mathrm{~b}$ \\
\hline BR 3123 & $197 b$ & $89 \mathrm{~b}$ & $0,89 \mathrm{a}$ & 69,36 a \\
\hline Z 8474 & $183 \mathrm{bc}$ & $86 \mathrm{~b}$ & $0,94 \mathrm{a}$ & $62 \mathrm{bc}$ \\
\hline Exceller & $176 \mathrm{c}$ & $84 \mathrm{~b}$ & $0,91 \mathrm{a}$ & $59 \mathrm{c}$ \\
\hline AG 122 & $188 \mathrm{bc}$ & $66 \mathrm{~b}$ & $0,90 \mathrm{a}$ & $63 \mathrm{bc}$ \\
\hline P 3071 & $174 \mathrm{c}$ & $83 \mathrm{~b}$ & $0,94 \mathrm{a}$ & $64 \mathrm{~b}$ \\
\hline DINA 657 & $174 \mathrm{c}$ & $82 \mathrm{~b}$ & $0,97 \mathrm{a}$ & $63 \mathrm{bc}$ \\
\hline $\begin{array}{l}\text { Média } \\
\text { Geral }\end{array}$ & 190 & 86 & 0,94 & 64 \\
\hline CV (\%) & 3,8 & 4,0 & 9,9 & 3,4 \\
\hline
\end{tabular}

${ }^{1}$ Média seguidas pela mesma letra não diferem significativamente pelo teste de Tukey $(\mathrm{P}<0,05)$.

*; **Resultado significativo $(\mathrm{P}<0,05)$ e $(\mathrm{P}<0,01)$ respectivamente.

Embora o aumento da saturação por bases não tenha influenciado o número de dias para 0 florescimento, na média dos híbridos testados, porém, a análise dentro de cada $\mathrm{V} \%$ indicou que os híbridos apresentaram diferença significativa. No V\% 65, o híbrido BR 3123 mostrou-se com florescimento mais tardio, diferindo significativamente porém, apenas, em relação aos híbridos P 3071; Z 8474; e Exceller. No V\% de 45, o híbrido BR 3123 mostrou florescimento mais tardio em relação aos demais híbridos avaliados (TABELA 3).

\section{CONCLUSÕES}

- A saturação por bases de $65 \%$ apresentou maior contribuição para os incrementos nos componentes do rendimento e no rendimento de grãos dos híbridos de milho avaliados.

- Os híbridos de milho apresentaram comportamentos diferenciados no rendimento de grãos, destacando-se no V\% $65 \%$, os híbridos P 3071 e Z 8474 enquanto que no $\mathrm{V} \% 45$, destacou-se o $\mathrm{C} 333$.

- A utilização de híbridos específicos para cada nível de saturação por bases mostrou-se uma importante ferramenta para o manejo da cultura do milho em áreas com quatro anos sob sistema plantio direto no cerrado.

\section{AGRADECIMENTOS}

À Agropecuária Nossa Senhora Aparecida, Uberaba, MG, que cedeu a área física e toda a estrutura e ao Prof.Dr. Walter Veriano Valério Filho da FEIS/ UNESP pelas sugestões na análise estatística.

\section{REFERÊNCIAS BIBLIOGRÁFICAS}

CAIRES, E.F.; BANZATO, D.A.; FONSECA, A.F. Calagem na superfície em sistema plantio direto. Revista Brasileira de Ciência do Solo, v.24, p.161-169, 2000.

CAIRES, E.F.; FONSECA, A.F.; MENDES, J.; CHUERI, W.A.; MADRUGA, E.F. Produção de milho, trigo e soja em função das alterações das características químicas do solo pela aplicação de calcário e gesso na superfície, em sistema plantio direto. Revista Brasileira de Ciência do Solo, v.23, p.315-327, 1999.

DEFELIPO, B.V.; RIBEIRO, A.C. Análise química do solo. Viçosa: Universidade Federal de Viçosa, 1981. 17p. (Boletim Extensão, 29)

EBERHAR, S.A.; RUSSEL, W.A. Stability parameters for comparing varieties. Crop Science, v.6, p.36-40, 1966.

GOMES, F.P. Curso de estatística experimental. 11.ed. São Paulo: Nobel, 1985. 466p.

HUE, N.V.; CRADDOCK, G.R.; ADAMS, F. Effect of organic acids on aluminium toxicity. Soil Science Society of America Journal, v.50, p.49-54, 1986.

MAGALHÃES, A.C.; SILVA, W.J. Determinantes genéticofisiológicos do milho. 2.ed. Campinas: Fundação Cargill, 1987. 452p.

MIYAZAWA, M.; PAVAN, M.A.; SANTOS, J.C.F. Effects of addition of crop residues on the leaching of $\mathrm{Ca}$ and $\mathrm{Mg}$ in oxisols. In: INTERNATIONAL SYMPOSIUM ON PLANT-SOIL INTERACTIONS AT LOW pH, 4., Belo Horizonte, 1996. Proceedings. Belo Horizonte: SBCS; EMBRAPA, CPAC, 1996. p.8.

PECHE FILHO, A. Critérios para avaliar a qualidade do plantio direto. O Agronômico, v.51, p.14-15, 1999.

PÖTTKER, D.; BEN, J.R. Calagem para uma rotação de culturas no sistema plantio direto. Revista Brasileira de Ciência do Solo, v.22, p.675-684, 1998.

RAIJ, B. van.; FURLANI, P.R.; QUAGGIO, J.A.; PETTINELLI JR., A. Gesso na produção de cultivares de milho com tolerância diferencial a alumínio em três níveis de calagem. Revista Brasileira de Ciência do Solo, v.22, p.101-108, 1998.

RAIJ, B. van.; QUAGGIO, J.A. Métodos de análise de solo. Campinas: Instituto Agronômico, 1983. 31p. (Boletim Técnico, 81)

RESCK, D.V.S. Plantio direto desafios para os cerrados. In: REUNIÃO BRASILEIRA DE FERTILIDADE DO SOLO E NUTRIÇÃO DE PLANTAS, 23., Caxambú, 1998. Resumos. Lavras: UFLA; SBCS; SBM, 1998. p.32-33.

SANTOS, J.C.F. Mobilização de cálcio e alumínio em solos ácidos por compostos orgânicos hidrossolúveis de resíduos vegetais. Piracicaba, 1999. 72p. Tese (Doutorado) - Centro de Energia Nuclear na Agricultura, Universidade de São Paulo.

SÁ, J.C.M. Manejo da fertilidade do solo no sistema plantio direto. In: GOMES, E.P.; KOCHANN, R.A.; GASSEN, D.N.; BORGES, G.O.(Ed.) Plantio direto no Brasil. Passo Fundo: EMBRAPA, CNPT; FUNDACEP, FECOTRIGO; FUNDAÇÃO $A B C$, 1993. p.37- 60.

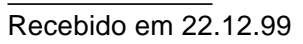

